\title{
How new sustainability typologies will reshape traditional approaches to loyalty
}

\author{
Neil Richardson ${ }^{1}$ (D)
}

Received: 5 May 2021 / Accepted: 4 January 2022 / Published online: 21 February 2022

(c) The Author(s) 2022

\begin{abstract}
The benefits of segmentation and loyalty programmes are well established however Business-As-Usual (BAU) models, whether online or traditional, only focus on customers' contributions to the 'bottom line'. Sustainable Development (SD) is inextricably linked to consumers and whilst some studies allude to 'green' segmentation, there are no loyalty ladders or frameworks predicated on Elkington's Triple Bottom Line (TBL). This study aligns with those who think the TBL should be the thread that runs through sustainability research. It looks beyond the question of why firms adopt sustainability and instead consider how they do so by investigating the changes needed for loyalty models and frameworks. The paper is positioned in the overlap between the SD and marketing domains. It facilitates conceptualisation by addressing some of the terminological confusion inherent in sustainability studies. It provides a working definition of SD and a rationale for (and definition of) the preferred term Sustainable Marketing (SM). Assuming marketers want to work in a more sustainable fashion, they need to adapt existing models or adopt new versions. With adaptation representing a smaller change to marketers' modus operandi, it is deemed more likely to be adopted than a radical change. This is conceptualised using two schools of thought, namely the Developmental and Critical schools. This study is positioned in the critical school as it posits that the traditional models are no longer fit for purpose and need adapting or replacing. This approach provides better understanding of why sustainability models (or frameworks) are needed and the need to shape practice, thus going beyond academic theory. Then the paper is in two main sections; first it critiques the BAU building blocks needed for loyalty ladders, namely a marketing orientation and segmentation frameworks. This paper advocates improving loyalty by adopting sustainable building blocks. Hence the second section uses existing adaptations, namely a sustainable market orientation, a sustainable stakeholder typology and a TBL-based segmentation framework (APPROVES), to create a new TBL-based SM loyalty ladder. This will provide a platform for discussion and future research.
\end{abstract}

Submitted to the special issue: "S.I. SUSTAINABLE MARKETING AND PERFORMANCE MANAGEMENT"in The Italian Journal of Marketing.

Extended author information available on the last page of the article 
Keywords Loyalty $\cdot$ Stakeholders $\cdot$ Sustainable marketing $\cdot$ Ladders $\cdot$ Segmentation

\section{Introduction}

Historically, a mindset existed that "economic growth was a prerequisite to improving the quality of life for humankind" (Belz \& Peattie, 2009, p. 7). Adam Smith's notion of voluntary exchange was developed in the nineteenth century by Ricardo, who proposed the law of 'comparative advantage' where both trading partners gained from their transactions. This could be argued to be the genesis of the 'dominant social paradigm' (DSP) ultimately leading to the neo-liberal agenda. However, the notion of companies being motivated by more than economic profit is not new. Kotler and Levy proposed the extension of marketing technologies into nonbusiness arenas in their seminal 1969 article 'Broadening the Marketing Concept'. They advocated Social Marketing, as the approach for social ideas and causes, being applied to places (cities, regions, nations) or people (Kotler \& Levy, 1969). Kotler later defined social marketing as:

"the design, implementation, and control of programs seeking to increase the acceptability of a social idea, cause or practice among a target group." (Kotler \& Armstrong, 2006, p. 239).

This resonates with the notion of equifinality by suggesting a range of approaches and different solutions to differing problems for differing groups. This is, arguably, not ideal from a sustainability perspective where global solutions are needed (Starkey \& Welford, 2001). Furthermore Kotler's 'inward-out' orientation may contribute towards increasing consumers' awareness of, say, greenwashing (Ramus \& Montiel, 2005). It certainly lacks specificity with respect to social responsibility, ethics, community or environmental sustainability. A later definition suggested Social Marketing is:

"the adaptation of commercial marketing technologies to the analysis, planning, execution, and evaluation of programs designed to influence the behavior of target audiences in order to improve their physical and mental wellbeing and or that of the society of which they are a part." (Andreasen, 1993, p. 1).

A caveat is that Social Marketing may be undertaken by commercial, non-profit, and government organizations (Kotler \& Lee, 2005) who will not necessarily be au fait with 'commercial marketing'. That said, Andreasen is advocating adapting existing models and frameworks. The International Social Marketing Association (ISMA) suggest Social Marketing:

"seeks to develop and integrate marketing concepts with other approaches to influence behaviours that benefit individuals and communities for the greater social good. Social Marketing practice is guided by ethical principles. It seeks to integrate research, best practice, theory, audience and partnership insight, to inform the delivery of competition sensitive and segmented social change 
programmes that are effective, efficient, equitable and sustainable." (ISMA, 2021).

Here the ISMA includes the term 'sustainable' whilst offering no indication of what is meant. Clearly the social element is addressed however there is no consideration of ecological factors.

In 1972 Kotler developed the social concept by introducing the 'Societal Marketing concept'. Societal Marketing being defined as:

"a principle of enlightened marketing that holds that a company should make good marketing decisions by considering consumers' wants, the company's requirements, consumers' long run interests and society's long run interests." (Kotler \& Armstrong, 2006, p. 642)

Societal Marketing "questions the implicit assumptions of marketing and more broadly the Dominant Social Paradigm" (Belz \& Peattie, 2009, p. 22). It extends Kotler's previous model to include community and consumer dimensions, however, it offers no specificity apropos ethics or environmental sustainability. It does introduce the notion of long-term relationships and 'society's long run interests' is broad enough to include ecological concerns. That said, Societal Marketing does not take into account the multiple intricacies of the sustainable business environment (Emery, 2012). Dibb et al (2006) discussed 'social responsibility and marketing ethics' which chimes with the ethical element of the ISMA definition. Brassington and Pettitt (2007) however link 'Societal' Marketing with ethical marketing as elements of Corporate Social Responsibility (CSR) which (they say) should inexorably lead to 'Sustainable' Marketing.

\subsection{Sustainability}

There are those who describe sustainability as a 'megatrend' (Lubin \& Esty, 2010; Prothero \& McDonagh, 2015). Megatrends are larger in magnitude, longer in duration and deeper in their effects than normal trends, fads or fashion (Mittelstaedt et al., 2014). They are complex in nature, extensive, unpredictable in their impact and are embedded in the contexts of their time (ibid). This paper posits that sustainability is a megatrend as it is vast in scope and "reflects the economic, political, cultural, philosophic and technological milieu of its day" (Prothero \& McDonagh, 2015, p. 254). If sustainability is indeed a megatrend, McDonagh and Prothero (2014) ask how will it be embedded throughout the entire organisation? This question is salient and central to this study.

Attempts to conceptualise and theorise sustainability still remain problematic (Kemper \& Ballantyne, 2019). Defining sustainability has proven to be challenging with many terms (i.e. 'ethical', 'organic', 'eco', 'green' or 'fair trade') being used interchangeably (Barkemeyer et al., 2009) when clearly they are not (Richardson, 2015, 2020). It is not surprising that some consumers find the terms confusing with new terms regularly being added to the sustainability lexicon such as upcycling (Bonera et al., 2020) and slow-fashion (Legere \& Kang, 2020). In companies, terms such as 
sustainability are vague enough to gloss over varieties in definition, stakeholder interest and involvement whilst being powerful enough to draw commitment from many different actors, including consumers, other companies and (inter)national organisations (Skov \& Meier, 2011). For this study for following definition is accepted:

"Sustainability is a collective term for everything to do with responsibility for the world in which we live. It is an economic, social and environmental issue. It is about consuming differently and consuming efficiently. It also means sharing between the rich and the poor and protecting the global environment while not jeopardizing the needs of future generations." (Jones et al., 2009, p. 125).

\subsection{Sustainable Development (SD)}

Jones et al (2009) suggest Sustainable Development (SD) can be traced back to the thirteenth century. Sadly, they offer no specifics however they concur with other commentators noting it reappeared in the environmental literature in the 1970s. When considering the origins of SD many cite the Brundtland Commission report "Our Common Future". By 1992, 70 different definitions of SD had been noted (Belz \& Peattie, 2009, p. 12). For this study Brundtland's definition is acceptable i.e. SD is 'development that meets the needs of the present without compromising the ability of future generations to meet their own needs' (WCED, 1987).

In the late 1990s Hart's 'Beyond Greening' brought SD to the wider business community (Hart, 1997). Soon after Elkington's 'Triple-Bottom-Line' (TBL) was introduced where the traditional economic focus was complemented with the foci of societal and environmental responsibility (Elkington, 1998). TBL can be described as an enduring, balanced approach to economic activity, environmental responsibility and social progress (Starkey \& Welford, 2001). This paper aligns with those who think Elkington's triple bottom line (TBL) (Elkington, 1998) should be the thread that runs through sustainability research and practice. Hult agrees insisting the TBL concept spans.

"different frameworks and acronyms in the more popular literature, such as the 3 E's (economic vitality, environmental quality, and equal opportunity), the 3 P's (people, planet, and profit), and the more traditional triple bottom line view (environmental integrity, economic prosperity, and social justice)" (Hult, 2011, p. 1).

The Hart and Elkington texts are considered to be two of the most important contributions on the subject of business sustainability development (Starkey \& Welford, 2001). The combined impact of these texts represented a step change in how businesses would be expected to operate. This approach, often paraphrased as 'People-ProfitPlanet', may represent an emergent branch of social science (ibid). The term Sustainable Development has been universally accepted rather than, say, Starkey \& Welford's 'Sustainability Development'. 


\subsection{Sustainability and loyalty}

When the core activity of a company is highly integrated with its socially responsible activities, consumers take a favourable attitude toward the organization (Mercadé-Melé et al., 2018). Similarly poor sustainability practices can lead to corporate reputational damage (Gomez-Trujillo et al., 2020). Such reputational damage impacts on organisational attempts to engender customer and stakeholder loyalty. Loyalty can be represented by the number of repurchases made by the consumer during a period of time (Mercadé-Melé et al., 2018). The 'green' aspect of sustainability has been shown to improve company or brand reputations and customer loyalty (Kemper \& Ballantyne, 2019).

Companies that act responsibly improve their image and consumer loyalty. They must carry out responsible activities that fit their images because this will benefit their credibility, altruism attribution and how they are perceived (Mercadé-Melé et al., 2018). Crittenden et al (2011) suggest sustainability should be in the DNA of companies. It should be embedded in their mission, goals, structure, operations and values (Rudowska, 2018). Clearly 'operations' covers loyalty programmes. Increasingly, companies are moving away from Business-As-Usual (hereafter BAU) practices. For example, using 'Purpose' rather than 'Mission' statements (Richardson et al., 2015) as they convey the message that sustainability is a key value (Rudowska, 2018).

The Brundtland report alludes to 'needs' as a key principle of sustainability (Belz $\&$ Peattie, 2009). The issue of consumers' needs is central to marketing. It has been suggested that Sustainable Marketing (hereafter SM) is the next stage in the conceptual development of marketing as it focuses on some of the significant long-term challenges facing society in the twenty-first century (Brassington \& Pettit, 2007). Some have argued that sustainability and SM "are two different concepts, while others have used them interchangeably" (Kemper \& Ballantine, 2019, p. 6). Therefore, it is appropriate to improve conceptualisation by clarifying SM terminology.

\subsection{Sustainable Marketing (SM)}

van Dam and Apledoorn (1996) coined the phrase 'sustainable marketing' in 1996 when discussing the inadequacy of green and/or ecological marketing. They largely ignored the social focus and failed to offer a definition of SM. They did however suggest the meaning of SM becomes apparent when the concept of sustainability is elaborated upon within the framework of marketing theory. They went on to argue that SM is marketing within, and supportive of, sustainable economic development (ibid). This is somewhat limited as it excludes for example not-for-profit organisations or social enterprises that may not contribute to economic development per se. Armstrong and Kotler (2012, p. 508) suggest SM is:

"socially and environmentally responsible marketing that meets the present needs of the consumers and businesses while also preserving or enhancing the ability of future generations to meet their needs." 
It can be argued that SM is an holistic long-term view of marketing which seeks to facilitate sustainable business practice and represents a true paradigmatic shift in marketing (Emery, 2012). "Sustainable marketing emphasises the TBL" (Belz \& Peattie, 2009, p. 30). Gosnay and Richardson (2008, p. 138) offered an early SM TBL-based definition. This contributed to an (ongoing) existential debate regarding SM in that some believe that modern business practices advocate selling more whereas 'sustainability' is about consuming less. Emery (2012) argues simply facilitating profitable exchanges between interested parties is no longer enough.

Martin and Schouten (2012) saw SM as the process of creating, communicating and delivering value to customers in such a way that both natural and human capital are preserved or enhanced throughout. The notion of delivering value is problematic. Freeman's idea that companies are 'out there creating value, making our lives better, and changing the world' (Freeman, 2008) fits better with modern discussions on value and co-creation (Richardson, 2015; Richardson \& Cassop Thomson, 2019; Coppola et al., 2020). Value can be created and taken but not given. Customers with sustainable values may seek (and take) such value from those they perceive to act sustainably.

Some academics used the term Sustainability Marketing (Belz \& Peattie, 2009; Belz \& Schmidt-Riedeger, 2010; McDonagh \& Prothero, 2014; Wiscicka-Fernando, 2018; Kemper \& Ballantine, 2019),

whilst others allude to sustainability-driven marketing. These terms have some merit, however, the notion of driving values is problematic as ultimately marketers cannot force customers to (say) be happy, satisfied or green. All marketers can hope to achieve is to create the circumstances where value-seeking customers can 'take value'. Even those who use Sustainability Marketing have also used Sustainable Marketing indeed Kemper and Ballantine (2019, p. 6) suggest:

"Several scholars see the merging of relationship. social, green and ethical marketing combining to create a new concept of 'Sustainable Marketing,."

SM is still overwhelmingly understudied (McDonagh \& Prothero, 2014). To improve conceptualisation, it is prudent to reflect on the usage of terminology. Kemper and Ballantine (2019, p. 10) cite research from Purani et al. (2014) who found that only $2 \%$ of articles in 10 of the most highly ranked marketing journals were devoted to sustainability. Hence, it is sensible to consider the current frequency of usage for the terms (Fig. 1) germane to this study.

As with Kemper and Ballantine (2019, p. 12), Fig. 1 is not a detailed metaanalysis nor is it an attempt to replicate previous studies. Rather, it provides a current snap-shot of 'searches' to provide comparisons. Applying a meta-analytical approach, Barkermeyer et al. (2009) had identified increasing usage of terminology related to sustainability in print media. This is not reflected in Fig. 1 which portrays 552 mentions of 'sustainable marketing' with 198,000 for Marketing' (in EBSCO). If sustainability is a megatrend (Lubin \& Esty, 2010; Prothero \& McDonagh, 2015) the logical conclusion to draw is that whilst it currently represents a niche, nascent area of study, research into sustainability (and its marketing variants) is likely to grow substantially. 


\begin{tabular}{|l|c|c|c|c|}
\hline \multicolumn{5}{|c|}{ Search findings for different terms } \\
\cline { 2 - 5 } Term & \multicolumn{4}{|c|}{ Database } \\
\cline { 2 - 5 } & Ebsco & Emerald & Google & Scholar \\
\hline Sustainable Market Orientation & $27(6)$ & $43(5)$ & 465 & 77.1 million (8010) \\
Sustainability Market Orientation & 1 & 35 & 359 & 50.7 million (4060) \\
Sustainable Marketing (SM) & $552(110)$ & 729 & 10,400 & 533 million (518000) \\
Sustainable Marketing Orientation & $7(1)$ & 43 & 101 & 44.3 million (4680) \\
Sustainability Marketing & $388(52)$ & 321 & 5,110 & 863 million (207000) \\
Market Orientation (MO) & $2511(237)$ & $>59,000(48)$ & 61 million & 372 million \\
Marketing & 198,000 & 239,000 & 403,0000 & 33.2 billion \\
\hline \multicolumn{7}{|c|}{ Databases accessed 18-04-21. Figures in brackets represent the term in a single string with a fixed order. } \\
\hline
\end{tabular}

Fig. 1 Search findings for different terms

Apropos using the better terminology, in Fig. 1 the academic databases have Sustainable Marketing (SM) identifying higher numbers than Sustainability Marketing. Whereas in the generic Google results the positions are reversed. This may reflect a gap between academia and the population in general. From a semantic point of view, no-one is using the term Sustainability Development; the universally accepted term is sustainable development. So why use Sustainability Marketing if a more widely used term with a better fit is available? Furthermore, Sustainability Marketing may be construed as the marketing of sustainability. The challenge this presents is that sustainability may not be prioritised and deemed yet another thing to address using IMC. Sustainable Marketing (SM) is holistic and should be embedded into the orientation of the organisation. For the purposes of this study Sustainable Marketing (SM) is preferred to Sustainability-driven Marketing or Sustainability Marketing and the following TBL-based definition is adopted:-

"Sustainable Marketing (SM) is principled and predicated on the foci of the Triple Bottom Line. SM decisions should be ethically and ecologically sound and companies should divert profits into People and Planet foci to enable implementation. Sustainable business practices must be informed by continuous dialogues with all stakeholders. Ultimately this is the only way to resolve the tensions between customer (and stakeholder) demands, long-term interests, companies' requirements, society's long run interests and the need for environmental balance." (Richardson, 2015, 2020, p. 19)

\subsection{A Market Orientation (MO)}

A Market Orientation (MO) alludes to the importance organisations attach to their marketplace including customers and competitors (Kohli \& Jaworksi, 1990). With an MO, customers should be placed at the heart of all key management decisions and all staff must 'buy-in' as it is not solely a burden for the marketing department (ibid). The Marketing department is however responsible for the adoption of Integrated Marketing Communications (IMC) which can facilitate 'buy-in'. IMC is predicated on message consistency, interactivity, being stakeholder-centric and having a 
strategic focus. IMC can also be argued to apply to the notion of Internal Marketing (IM) which is defined as.

"using a marketing-like approach to overcome organisational resistance to change and to align, motivate and inter-functionally co-ordinate and integrate employees towards the effective implementation of corporate and functional strategies in order to deliver customer satisfaction through a process of creating motivated and customer orientated employees." (Rafiq \& Ahmed, 2000, p. 454)

Managers must use IMC to ensure information flows (well) and is shared across departmental boundaries and even organizational frontiers (Porcu et al., 2020). This applies to all organisational types and sizes even micro-enterprises where marketing is often allocated to a multi-tasking individual. Kohli and Jaworski (1990) suggested an MO includes the organisation-wide, inter-departmental dissemination of market intelligence pertaining to current (and future) customer needs and responsiveness to it. It should be noted that the term search resulting in Fig. 1 suggests the term MO is used considerably less than the generic 'Marketing'. For the purposes of this paper an MO is defined as:

“understanding current and future customers' needs and wants in order to develop products and services that offer value for the customer, distinctive from the offers of other companies, which can be profitably produced. Hence companies must recognise the importance of continuing research in the marketplace and ongoing relationships with customers." (Richardson et al., 2015, p. 25).

This paper posits the notion that companies who do not adopt an MO will be less likely to achieve the loyalty they seek.

\subsection{Schools of thought: the drivers for challenging BAU and acting sustainably}

Mittelstaedt et al (2014) suggested two different schools of Marketing thought exist; the Developmental School sees markets and marketing systems as part of the solution to the problems of the human condition; the Critical School sees markets and marketing as part of the problem. What they "have to say about sustainability rests on the acceptance or rejection of the context in which questions of sustainability have emerged" (ibid, p. 253).

Critical Scholars are more suspect of the social consequences of markets and marketing and have long played a key role in challenging BAU. Critical Marketers (Brown, 1995; Brownlie \& Saren, 1992; Brownlie et al., 1999; Fuller, 1999; Tadajewski \& Brownlie, 2008 amongst others) provide useful reminders of why models (and frameworks) need adapting (or new versions adopted) whereas Developmental Scholars (see McDonald, 2017) provide continuity and may be resistant to change. They often criticise Critical Scholars for not providing useful terms and tools (see Fig. 1). For example, van Dam \& Apledoorn (1996), who coined the phrase 'Sustainable Marketing' in 1996, aligned with the critical school (see their paper in 
Tadajewski \& Brownlie, 2008), however, they did not offer a clear definition nor did they offer tools or frameworks to help practitioners. Many years later, Critical Marketers Gosnay and Richardson (2008) offered a TBL-based Sustainable Marketing Benchmarking Framework. This was subsequently updated (see Richardson, 2015, 2018).

Developmental Scholars (Christopher et al., 1991; Harridge-March \& Quinton, 2009) have advocated loyalty ladders as a relatively easy way of understanding behavioural loyalty by helping companies to segment customers (and prospects) according to their levels of loyalty (Richardson, 2015; Richardson et al., 2015). The BAU traditional 'ladders' still focus purely on the customers' contribution to the 'bottom line' whilst ignoring customers' values (often ecological and ethical) and other stakeholders. This paper is positioned in the Critical School as it addresses the Developmental School's failure to offer a TBL-based alternative framework.

The duality of the 'Schools' (Mittelstaedt et al., 2014) can be found throughout marketing domains (Fig. 2). Apropos loyalty, Critical Marketers identify 'unsustainable' aspects which (they argue) need to be discussed more frequently in academia. Many large service providers have customers who are not totally satisfied with their services. Often the consumer feels "locked-in" (Harrison et al., 2012; Jackson, 2005; Murray \& Haubl, 2007; Sanne, 2002) or a possibly unhealthy sense of compulsion (Guido et al., 2020). The effort needed to switch suppliers tends to make customers stay with the existing provider. This is 'unsustainable' and results from inertia, risk aversion, apathy, "working life conditions, which favour a work-and-spend lifestyle, the conditions of urban living or the effects of pervasive marketing" (Sanne, 2002, p. 286).

\subsection{Summary of Introduction Chapter}

A goal of this paper is to improve conceptualisation by providing definitions relating to sustainability (and Sustainable Marketing). Whilst this study is located in the Critical School, it resonates with those who studied BAU loyalty (Dick \& Basu, 1994; Harridge-March \& Quinton, 2009; Harris \& Goode, 2004) and those where loyalty is linked to responsible actions (Aksoy, 2013; Bertoli et al., 2020; MercadéMelé et al., 2018).

This paper will use the (provided) definition of a Marketing Orientation (MO) as the underpinning for adopting a Sustainable Marketing Orientation (SMO) prior to

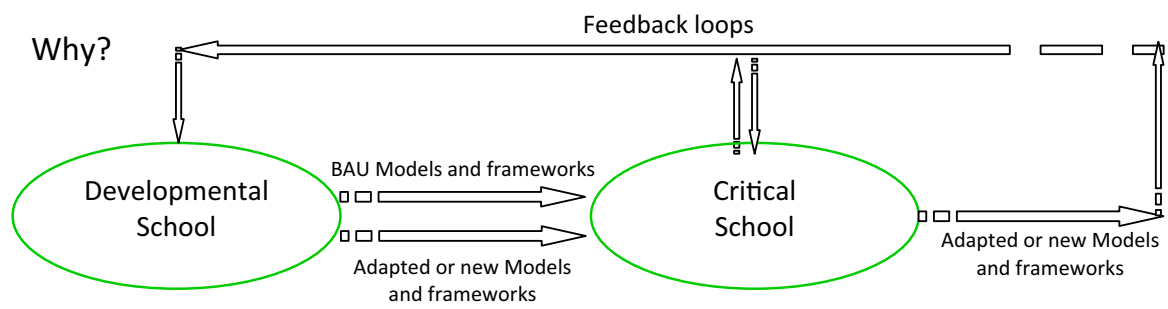

Fig. 2 Critical v Developmental Schools 
undertaking segmentation. Segmentation frameworks form the building blocks for loyalty ladders and have traditionally focused on optimising the profitability garnered from customers (aka BAU). Changing production and consumption systems cannot be achieved without changing marketing mindsets and practices (Belz \& Peattie, 2009). There is little or no research on using the TBL to shape segmentation and loyalty approaches.

Hence, this study will (critique and) develop the traditional building blocks of loyalty by viewing them through the lens of TBL-based sustainability. In doing so, this paper contributes to those who seek to look beyond the question of why firms adopt SM and instead consider how they do so by investigating the mechanisms that enable effective (SM) adoption (Clarkson, 1995; Gosnay \& Richardson, 2008; Musgrave \& Raj, 2009; Mitchell et al., 2010, 2013; Crittenden et al., 2011, 2013; Garcia et al., 2014; Wiscicka-Fernando, 2018; Richardson \& Cassop Thompson, 2019; White et al., 2019; Legere \& Kang, 2020). Finally, two goals of this paper are to offer a TBL-based segmentation framework and loyalty ladder to facilitate sustainability adoption. This study concludes with recognition of the limitations therein and offers thoughts on potential future research.

\section{The Business-As-Usual (BAU) building blocks of loyalty}

Marketers wanting to work sustainably, cannot continue with BAU, simply using traditional models. Rather they need to adapt existing models or adopt new versions apropos their Marketing Orientation (MO), segmentation and loyalty.

\subsection{Segmenting consumers and stakeholders}

Segmentation, as one of the building blocks of loyalty, inherently involves consumer analysis. Organizations must be proactive in gathering information about consumers' interests (Mercadé-Melé et al., 2018). Under BAU, segmentation largely gathers data on the economic value garnered from customers. This shapes the organisation's communications and is remiss as 'Sustainability' can enhance not only corporate reputations but also stakeholders' acceptance and perceptions of companies' activities (Gomez-Trujillo et al., 2020). Freeman provided a language and framework for examining how companies relate to stakeholders. It established legitimacy for parties other than shareholders whose interests can shape managers' actions (Margolis \& Walsh, 2003). Freeman's stakeholder theory shaped the dominant theoretical response to the economists' shareholder-profit only hegemony (ibid). He defined stakeholders as groups or individuals who can affect (or be affected by) the achievement of the organisation's objective (Freeman, 1984). The 'affect' can be beneficial or harmful. This was developed to include those whose rights may be violated or should be respected by the business or claim ownership in organisational activities (Mendes et al., 2009).

Different stakeholders often compete for the control of resources which can be material, social, ideological or symbolic (Mitchel et al., 1997). Stakeholders may 
be institutions with interests in a project' or those who have, or claim, ownership (Mendes et al., 2009). 'Primary' stakeholders are those without whom companies cannot survive whereas 'Secondary' stakeholders influence or affect (or are influenced or affected by) companies but are not essential for survival (Clarkson, 1995). A power-based ranking system exists starting with only having interest (i.e. lowpower) to having an affect (medium) to assuming ownership (high) (ibid). Increasingly, academics insist shareholders are only one of a number of stakeholders (Jackson, 2005; Jones et al., 2009; Letza et al., 2004; Richardson, 2015, 2018).

Stakeholder salience is the degree to which managers give priority to competing stakeholder claims (Mitchell et al., 1997). Marketers must recognise the degree of urgency as well as the interest and/or power stakeholders possess. Shareholders are primary stakeholders and thus at least moderately salient however it is heightened shareholder urgency that really attracts CEO attention (Agle et al., 2008). Figure 3 clearly illustrates how an organisation may have stakeholders with differing combinations power, legitimacy and urgency resulting in of different saliences (Mitchell et al., 1997; Richardson, 2015; Richardson et al., 2015).

In practice, marketers refer to 'publics' rather than 'Non-stakeholders'. Publics are stakeholders who may be interested (in organisations) but are not directly involved. However, today's 'public' could easily become tomorrow's engaged stakeholder. Furthermore, power, legitimacy and urgency can change for any particular group or stakeholder-manager relationship (Agle \& Mitchell, 2008). Stakeholders

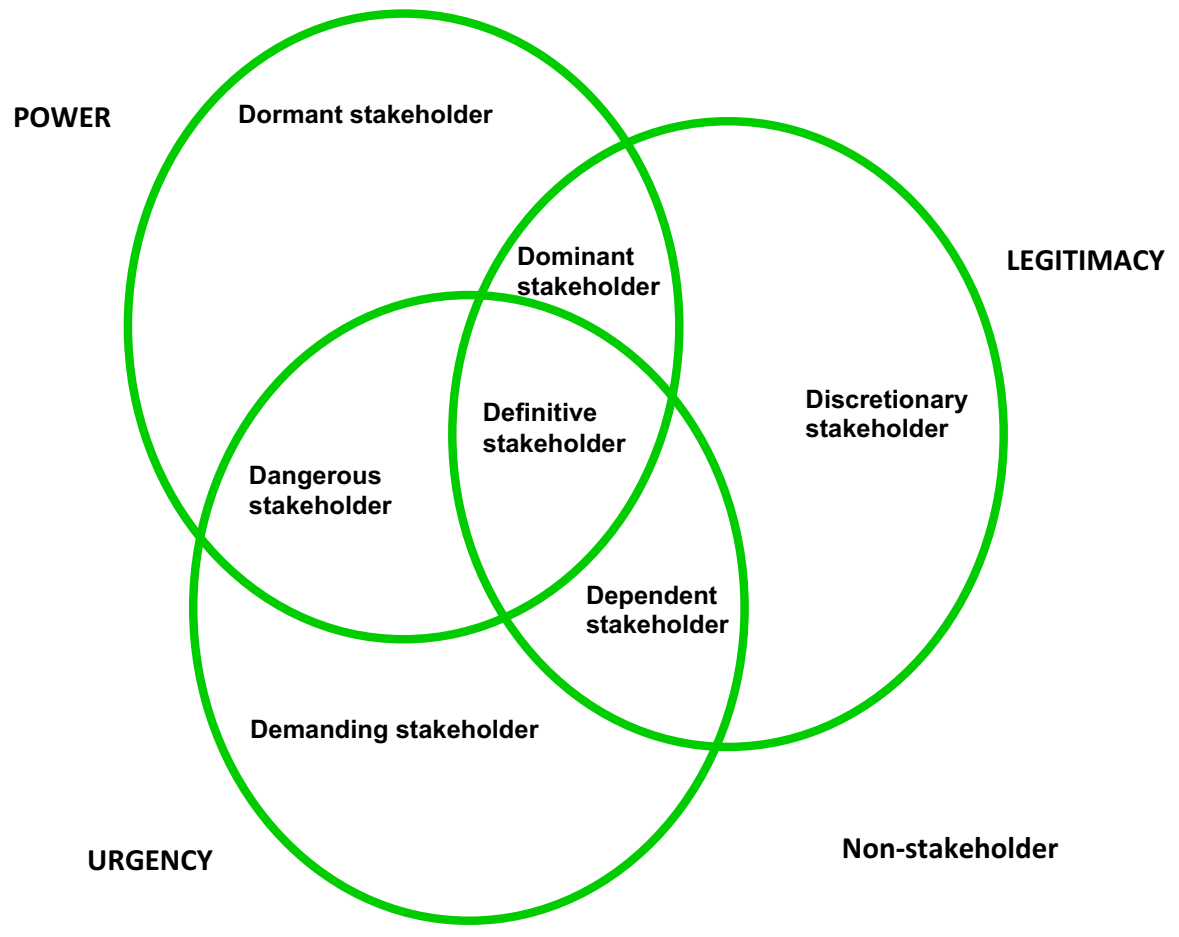

Fig. 3 Stakeholder typology with three attributes present ( Source Mitchell et al., 1997, p. 874) 
may only be interested in time-limited projects or selective corporate objectives. Such mapping tools are often only a snapshot and neither predict future changes nor provide solutions for practitioners.

Strong stakeholder theory suggests all stakeholders, irrespective of attributes and resulting salience, are dealt with in an equal matter i.e. whether a Definitive Stakeholder or say a Dormant Stakeholder (Fig. 3). A critique of strong stakeholder theory is that it leaves managers and directors making subjective judgments on which stakeholders to address. The criteria for such decisions is often opaque which can lead to managers being unaccountable for their stewardship of the firm's resources. Hence, managers may not be meaningfully evaluated in any principled way (Jensen, 2008) and power relations may not be adequately addressed (Barkemeyer, 2009).

Studies have consistently found that with a stakeholder focus, corporate performance is very much the same. This suggests stakeholder-focused management does no harm to shareholder interests while also benefiting a larger constituency (Agle \& Mitchell, 2008). It is well-established that organisations who assume stakeholder passivity are taking risks as often this is simply not the case. Margolis and Walsh (2003) cite Ranganathan (1998) who listed 47 initiatives where investors have 'pressured' firms to be more responsive to social problems. Others have criticised scholars for paying too little attention to the relationship between the firm and society, focusing too much on processes whilst neglecting analysis of the firm's societal effects (Walsh et al., 2003). This is remiss as ethics, social responsibility and sustainability "have moved from marginal to mainstream and we can no longer say that the business of business is purely business" (Emery, 2012, p. 11). Figure 3 provides a basis for segmentation hence it appropriate to consider how the viability of a segment is evaluated.

\subsubsection{Segmentation frameworks}

Segmentation involves breaking down a heterogeneous population into smaller homogenous segments. This is a challenge for many marketers; indeed, Professor Malcom McDonald describes the segmentation chapter in his practitioner text as "the only difficult chapter in this book" (McDonald, 2017, p. 63). He implores readers to read the chapter as segmentation really is the key to commercial success citing research in the Harvard Business Review (HBR) "where 85\% of US product launches had failed simply because of poor market segmentation" (ibid, p. 74). The viability of existing segments will have to be re-evaluated during the audit stage of a marketing plan (Richardson, 2020; Richardson et al., 2015) as Marketers cannot assume that the original segment (whether B2C or B2B) will be appropriate for new marketing objectives. Furthermore, the means of communication with segments may also need to be reviewed (ibid). Three well-known BAU (economic focus) segmentation frameworks are 'DAMP', 'DASA' and 'MASS' (Fig. 4).

Segments have to be constructed judiciously when considering multiple values and motivations of individual consumers (Guido et al., 2020). If the segment is too broad it may dilute the impact of communications campaigns. If it is too narrow, it may not provide the Return on Investment (RoI) or Return on Marketing Investment 


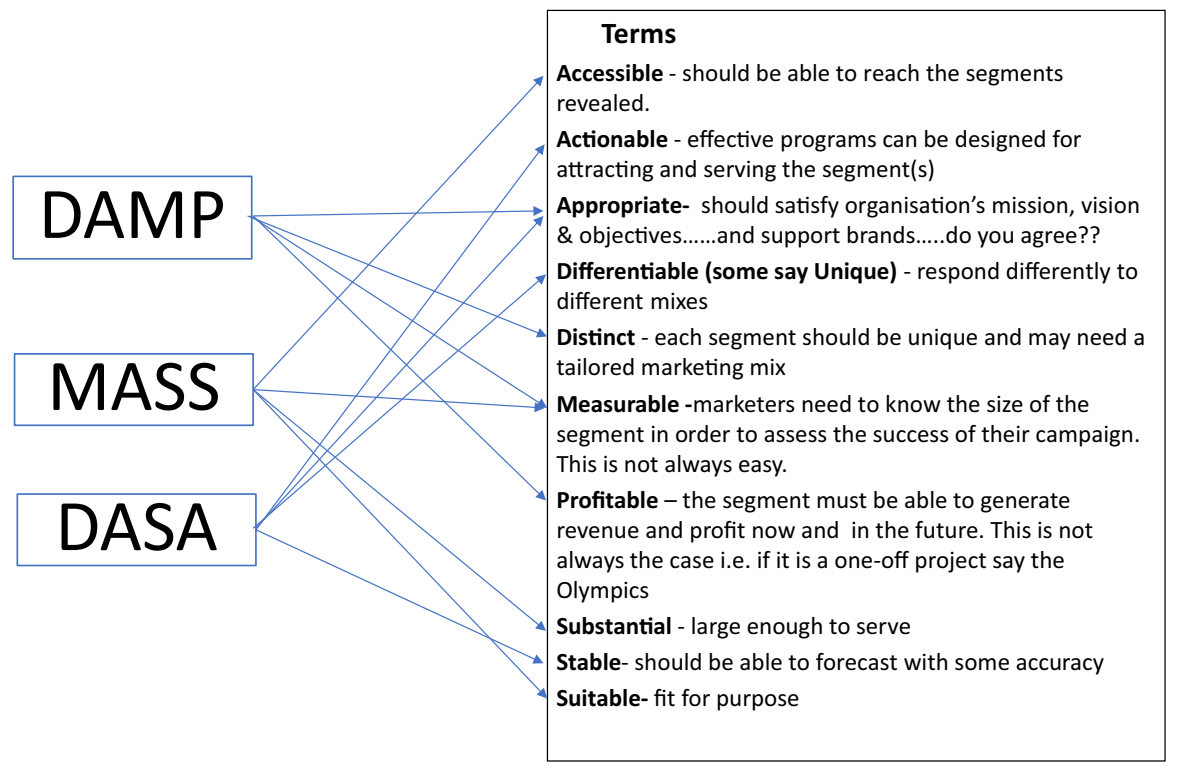

Fig. 4 The 3 most widely used segmentation frameworks

(RoMI). As discussed, these frameworks focus on the traditional economic bottom line and there is more to sustainable segmentation than is covered therein.

\subsection{Loyalty}

The notion of loyalty has long occupied the minds and efforts of marketing academics and practitioners. Dick and Basu (1994) suggested loyalty is not just about attitudes towards products or services, but also behaviour i.e. it includes the repeat(ed) purchase of said goods or services. This encouraged Marketers to consider the Customers' Life-Time Value (CLTV) rather than single transactions. Subsequently, the definition has been expanded (see Oliver, 1997) however the basic concept remains unchanged. The literature on loyalty recognises how it derives from satisfying customers seeking benefits (Parasuraman et al., 1991; Bitner, 1995; Mercadé-Melé et al., 2018) and values including co creation of value (Coppola et al., 2020; Richardson \& Cassop Thompson, 2019). The literature suggests loyal customers may increase income, buy additional products or services, generate Word of Mouth (or 'Word of Mouse' online), reduce costs and allow companies to amortise marketing (and sales) costs across the CLTV. Clearly these benefits represent sources of competitive advantage which are difficult to copy.

The benefits may be clear however engendering customer loyalty is anything but easy. Satisfying customers is seen as sine qua non for engendering loyalty. Verhoef (2003) defined satisfaction as the emotional state that occurs as a result of customers' interactions with the firm over time. This suggests that satisfaction involves 
comparing what customers expect will happen and what they actually experience. Genuine satisfaction often comes after repeated experience (purchases) (ibid). Furthermore, loyalty is predicated on trust which builds upon factors such as reliability and consistency, i.e. fulfilling the promises made (Bitner, 1995), to the same standard (Bertoli et al., 2020), 'being there' when required, going the extra mile, being treated equitably (Harris \& Goode, 2004). The last of these is particularly interesting as the loyalty literature tends to underplay the importance of equity. Indeed, it is suggested that loyal customers may be less sensitive to price levels than those who are first time customers. Harris \& Goode advocate the importance of equity, arguing that perceived value, satisfaction, service quality are key requirements of a relationship whereas trust is the key, central factor (ibid). Their finding that trust is the key and that loyalty may follow is supported by more recent studies (Bertoli et al., 2020).

\subsubsection{Loyalty Ladders}

A relatively easy way of categorising behavioural loyalty (what customers or prospects do) is the loyalty ladder (Richardson, 2020; Richardson et al., 2015). BAU Loyalty ladders (Fig. 5) help companies to segment customers according to their levels of loyalty and contribution to the bottom-line.

The ladders allow the segmentation of customers (and prospects) with a view to moving them up the ladder. Harridge-March and Quinton (2009) revised the traditional ladder to take into account the importance of social networks. In the top category 'Devotees' contribute regularly and are developing social ties; Insiders are deemed experts in specific topics who post regularly. Finally, 'Lead members' or 'Celebrities' are the most influential and active (ibid). 'Evangelists' are deemed comparable with the traditional 'Advocates'.

\section{Adapting BAU loyalty building blocks to incorproate the TBL}

Despite definitions of sustainability and SM existing for decades, very few studies have developed the link between sustainability and marketing strategy (Kumar et al., 2012). Marketing academics need to create new models or adapt existing ones so that practitioners can adopt sustainability in strategic marketing practices (ibid). Adapting models to incorporate sustainable practices is not new, indeed Peattie and Belz (2010) refined elements of the extended Marketing Mix for Services 7Ps (Product, Price, Place, Promotion and People) to offer the concept of 5Cs i.e., Customer solution, Customer cost, Convenience, Communications and Co-relations. Alternative Cs have subsequently arisen e.g. Richardson et al (2015) prefer Customer Benefits to solution as it provides a focus on what customers seek rather than what the provider offers. Increasingly, businesses are becoming exposed to the risks associated with the gap between what they say and what they do (Jones et al., 2009, p. 305). This paper contributes to those offering the loyalty or segmentation tools to be used by practitioners (see Mitchell et al., 2010). Hence it is prudent to propose adaptations to the BAU building blocks needed to create the loyalty ladder (Fig. 5). 
Fig. 5 Traditional and social media loyalty ladders. Adapted from Christopher et al (1991), Harridge-March and Quinton (2009) and Richardson et al (2015)

\begin{tabular}{|c|c|}
\hline Traditional & Social media \\
\hline $\begin{array}{l}\text { Advocate-actively } \\
\text { promotes brand to others } \\
\text { Supporter-an influencer } \\
\text { rather than a customer } \\
\text { Client- a customer who } \\
\text { makes repeat purchases } \\
\text { Customer- an individual } \\
\text { who purchases your } \\
\text { product or service } \\
\text { Prospect- finds the } \\
\text { company's offer of } \\
\text { interest } \\
\text { Suspect -researches a } \\
\text { brand but is not } \\
\text { interested }\end{array}$ & $\begin{array}{l}\text { Evangelist- actively promotes } \\
\text { social site to others } \\
\text { 'Lead members' or } \\
\text { 'Celebrities' - highly active. } \\
\text { May influence others } \\
\text { Insiders -seen as experts in } \\
\text { specific topics and post } \\
\text { regularly. } \\
\text { Devotees- contribute } \\
\text { regularly and are beginning to } \\
\text { develop social ties } \\
\text { Mingler- mature tourist, } \\
\text { perhaps, who posts } \\
\text { comments but without any } \\
\text { regularity or frequency. } \\
\text { Newby-an individual who has } \\
\text { just started to post comments } \\
\text { Tourist-post comments but } \\
\text { lacks engagement with the } \\
\text { network } \\
\text { Lurker -observes and may join } \\
\text { the network }\end{array}$ \\
\hline \multicolumn{2}{|c|}{$\begin{array}{l}\text { Adapted from Christopher et al (1997); Harridge- } \\
\text { March \& Quinton (2007); Richardson et al (2015) }\end{array}$} \\
\hline
\end{tabular}

\subsection{Adapting an MO to become an SMO}

The first adaptation this paper advocates is from an MO (see 1.5) to a Sustainable Market Orientation (SMO). The adoption of an SMO offers the potential to produce significant long-term benefits for both primary and secondary corporate stakeholders (Mahmoud, 2016; Mitchell et al., 2010). This paper builds on the work of Crittenden et al (2011) who offered a model to drive market-oriented sustainability research and provide directions for sustainability theory, research, and practice. They adapted MO to produce their own model of an SMO. For the purposes of this paper (also drawing on Mitchell et al., 2010; Hult, 2011; Kumar et al., 2012; Sinčić Ćoric et al., 2020), SMO is defined as where an organization:

"strategically aligns itself with the market-oriented needs and wants of customers and other stakeholders concerned with social responsibility issues involving economic, environmental, and social dimensions. An SMO is predicated on the TBL and involves adopting a balanced and equitable integrational management of environmental, social and economic resources." 
Having adopted a definition for an SMO, the next BAU building blocks to adapt involve segmentation.

\subsection{Segmenting sustainable stakeholders}

Segmentation, targeting and positioning (STP) are key parts of SM's strategic decisions (Rudowska, 2018). This paper focuses on TBL-based segmentation whilst recognising the need for 'targeting' and 'positioning' to be seen through the prism of SM. In their analysis of SM related articles, Kemper and Ballantyne (2019) identified only 5 instances of green or ecological segmentation. They found no articles relating to TBL-based segmentation. Considerable attention has been given to companies being attacked online about aspects of their social and environmental performance (Belz \& Peattie, 2009). The greater focus on 'green' segments is not surprising as consumers are increasingly exposed to information about sustainability issues such as climate change (ibid). Furthermore, a bias towards ecological and economic studies has always existed in the sustainability literature (Barkemeyer, 2009; Musgrave \& Raj, 2009; White et al., 2019; Sinčić Ćoric et al., 2020). This may in part be because social SM activities have less significant impacts on brand image (Jung et al., 2020).

Sustainable segmentation is seen as essential with SM (Wiscicka-Fernando, 2018) as it identifies how people perceive and respond to sustainability issues (ibid). Previous studies focused on segmenting 'elusive' green consumers (Peattie, 1992; Worthington, 2013; Young et al., 2010) with mixed results (Oates et al., 2008). Indeed, the term 'green' can be problematic as clearly different shades of 'green' consumers exist with some being 'light' green whilst others are heavily involved and self-identify as voluntary simplifiers (Oates et al., 2008; Richardson, 2015; Young et al., 2010).

The stakeholder concept has been important in helping marketing strategists to understand the implications of the sustainability agenda (Belz \& Peattie, 2009). Drawing on the sustainable consumer literature (Fuller, 1999; Jackson, 2005; Richardson, 2015) this study advocates conflating the traditional segments (Fig. 3) with the TBL to produce a Sustainable Segmentation Typology (SST).

The SST (Fig. 6) should improve understanding of segmentation however critical scholars would argue that all such typologies have limitations e.g. 'Power' sources may be identified however relationships may not. Furthermore, it does not forecast where the stakeholders may be in the future or that they may only have interest in aspects of an organisation's activities, say a project. The terms within the SST may need sub-sections to reflect other research and the reality. Young et al (2010) investigated voluntary simplifiers who strive to survive in a mode of sufficiency and demonstrated more complex decision-making processes than other consumers. Voluntary simplifiers were critical of certain sources and willing to search harder for information which, when provided by third parties, tends to be less biased (ibid). They would most likely be 'segmented' (Fig. 6) amongst 'Eco warriors' however depending on other values they could be Pro-Eco, Pro-Eco-Social or Sustainable Stakeholders. The SST is still relevant as it informs how IMC may need to be 


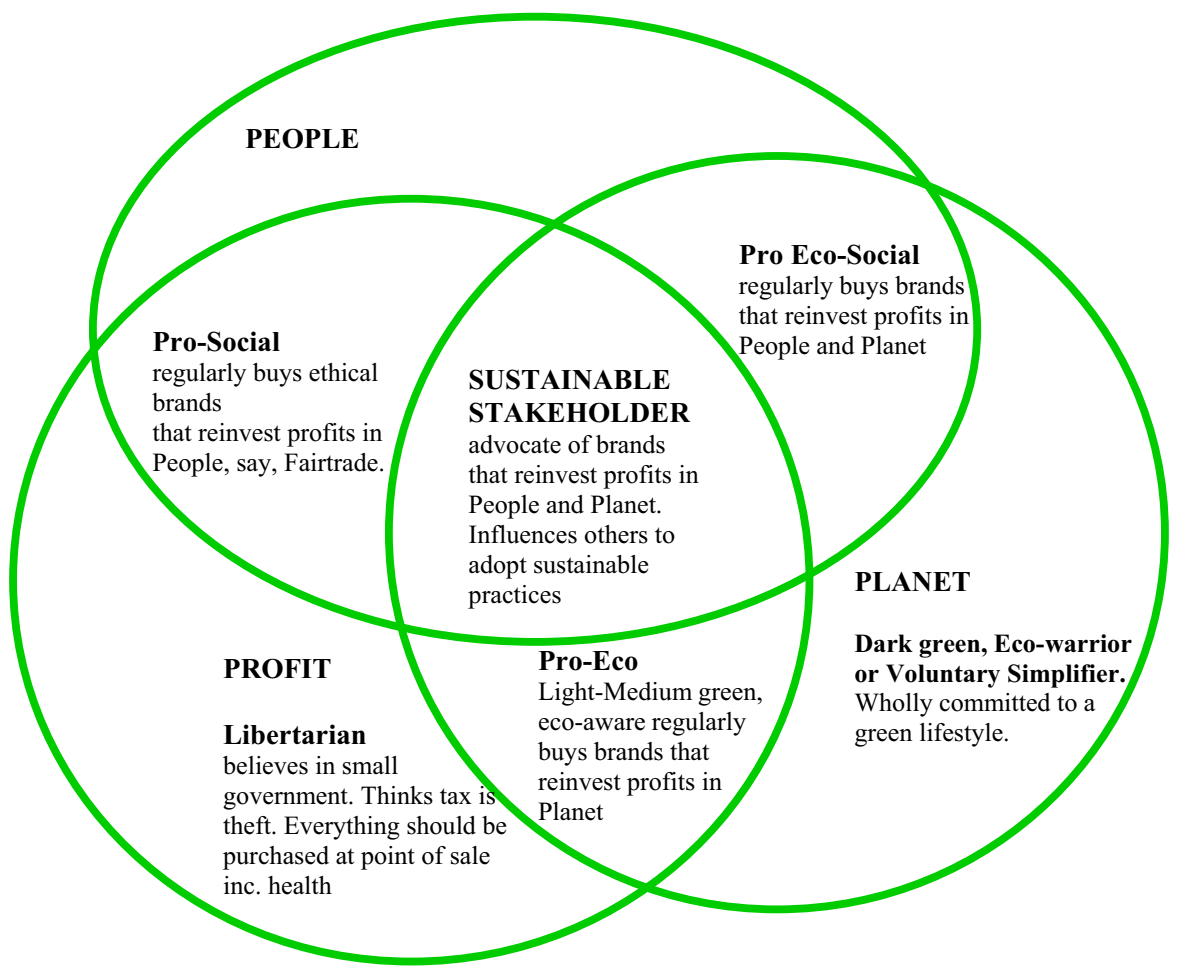

Fig. 6 Sustainable stakeholder typology. Source adapted from adapted from Mitchell et al (1997), Jackson (2005) and Richardson (2015)

tailored (Porcu et al., 2020) to clarify, say, contradictory claims or terminological confusion.

As discussed, consumers may self-identify as sustainable and can be segmented. Hence the sustainable segments' viabilities must be seen through a sustainable lens (Fig. 7).

The TBL-based APPROVES framework (Richardson, 2020) embeds sustainability into the process that establishes a segment's viability. It shares some limitations with its traditional predecessors (Fig. 4). As good as a segment may appear, its value will be wasted unless the whole organisation embraces it. Too often, critical insights are not realised, because of a lack of senior-management buyin (McDonald, 2017). Furthermore, poor Internal Marketing (Rafiq \& Ahmed, 2000) and IMC (Porcu et al., 2020) may result in other functions (not directly involved) feeling disconnected and lack engagement.

There is agreement that consumers experience involvement when objects or events 'connect' to important goals or centrally held sustainable values e.g. being environmentally friendly often featuring intense emotional commitments (Richardson, 2015; Sheehan, 2010) that in turn increasingly influence their patronage 


$\begin{array}{ll}\begin{array}{l}\text { Term } \\ \text { Accessible }\end{array} & \begin{array}{l}\text { Comment } \\ \text { etc each segment should be unique and may need a tailored marketing mix. }\end{array} \\ \text { Profit } & \begin{array}{l}\text { The segment must be able to generate revenue profitably now and in the future. } \\ \text { People \& Planet } \\ \text { The segment must be willing to buy goods and services where some profit is invested in supporting ethical } \\ \text { (or social) practices and invested in reducing ecological harm. }\end{array} \\ \text { Return } & \begin{array}{l}\text { Marketers should differentiate consumers by their profitability and their involvement in a category. That } \\ \text { helps to prioritize investments in business actions intended to promote segment growth. }\end{array} \\ \text { Oppportunity } & \begin{array}{l}\text { Opportunity considers frequency or depth of use, knowledge or expertise and the amount of money spent } \\ \text { (or available) by customers. It considers the time they spend thinking, researching, learning, talking about }\end{array} \\ \text { Values } & \begin{array}{l}\text { The segment should be aligned with the company's mission (or purpose), vision \& objectives. These should } \\ \text { fit with the brand. }\end{array} \\ \text { Estimable } & \begin{array}{l}\text { Marketers should be able to forecast with some accuracy. The segment must have long-term prospects } \\ \text { unless it is for a specific project. } \\ \text { It must be large enough (or alternatively in small segments the customers must have sufficient disposable } \\ \text { income) to provide revenue and profit (Rol) or to achieve other objectives (RoO). }\end{array}\end{array}$
(Source adapted from Richardson, 2020, p183)

Fig. 7 Sustainable segmentation framework approves

decisions (Carpenter \& Moore, 2006). Pro-environmental behaviour involves purchasing and non-purchasing behaviour (Jackson, 2005). Green consumers' contexts and values frame purchases apropos the motivation to pursue green criteria. It is influenced by the consumer's knowledge of the relevant issues as well as how previous purchase experience influenced the consumer (Young et al., 2010). The APPROVES framework benefits from being more relevant to the increasing numbers of people who use ecological and ethical heuristics (Mitchell \& Harris, 2005 ) to buy goods and services.

\subsection{Sustainability and loyalty}

If sustainability involves anticipating, managing and evaluating all human activity in the business environment and beyond in order to maintain social, environmental and economic activity (Emery, 2012), then the role of stakeholders apropos loyalty must be considered. Worryingly, few companies have a working definition of loyalty (Aksoy, 2013) and, as such, may not how it is engendered. Figure 8 portrays the Sustainable Marketing (SM) Loyalty Ladder (Fig. 8).

Critiques exist for TBL-based and BAU ladders (Fig. 5). Clearly, neither of the BAU ladders embrace non-customer stakeholders nor (explicitly) the increasing ethical and ecological demands of consumers. Apropos the SM Loyalty Ladder, marketers could choose to focus on the economic bottom line and ignore the ethical and ecological dimensions. This could lead to customer attrition if the company's values no longer align with sustainable consumers (Jackson, 2005).

None of the ladders explain how to move incumbents (presumably) upwards and the SM Loyalty Ladder does not provide instructions on how to move customers across from economic to ecological and/or ethical practices. Both provide challenges for organisational IMC (Porcu et al., 2020). SM, like Social Marketing, will be used to try to effect individual-level behavior change however "many people do not have full information, or lack the processing capability in 


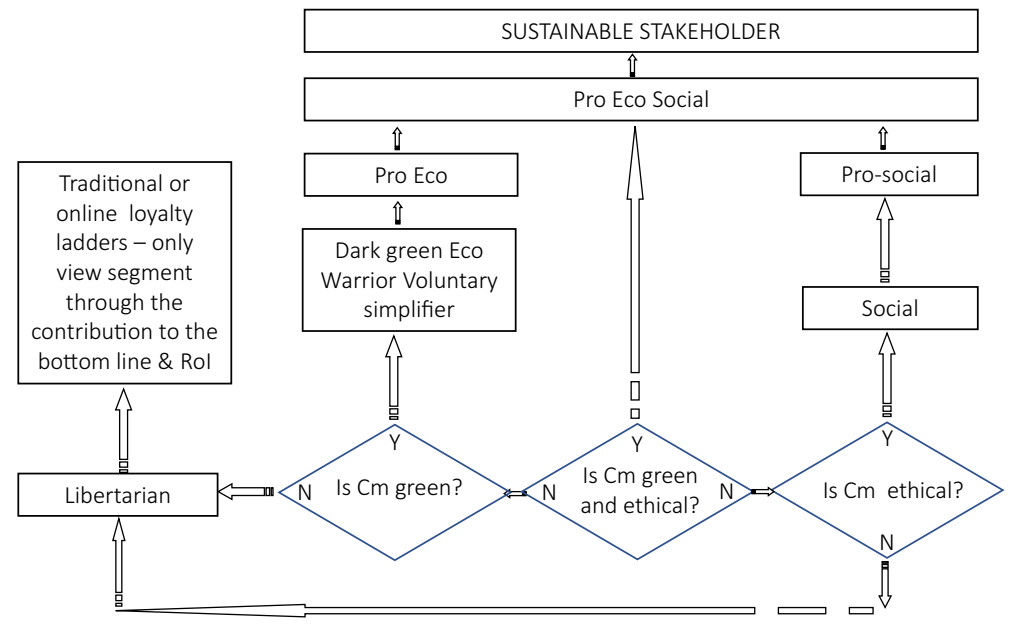

Fig. 8 Sustainable marketing (SM) loyalty ladder

certain situations to make logical choices" (Kennedy, 2015, p. 2). Apropos IMC, Marketers should target responsive segments with sustainability appeals and interventions should be tailored to reflect the specific needs and motivations, barriers, and benefits of the target consumer (White et al., 2019). Marketers will have to tailor their communications to their audience which may involve different communications mixes for the respective sub-segments (see the SST in Fig. 6).

\subsection{Sustainability and organisational culture}

The nature of the organisation may also shape the approach to using the SM loyalty ladder. On one issue a corporation might have exemplary behaviour but on another it may perform poorly and need corrective action (Jones et al., 2009). Some companies will have inclusive cultures whereas others will be authoritarian. Progressive marketers are, however, recognising that consumers are not only more discerning, but they have more choice than ever before. Adapting an organisation to become sustainable (i.e. using the SM Loyalty Ladder) may be a difficult task for companies that have operated in markets for many years, often managed by the same people. Such managers may treat these issues more as activities that create an image for the company rather than a sine qua non for modern companies that to ensure long term growth (Rudowska, 2018).

Creating sustainable value may be subject to time constraints or may be impossible given certain resource allocations. Specifically, while some are able to implement sustainable practices immediately others may need to accrue the resources to initiate changes (Pacheco et al., 2010).

Every firm has its own culture, which can be a great source of competitive advantage (Porcu et al., 2020). The culture determines "how firms understand the relationships between its members; the organizational structure; the flexibility enjoyed 
by employees to discover new ideas and share them both vertically and horizontally; and the degree of agility with which a firm is able to adapt to changes in its operating environment" (ibid, p. 436). Not all firms will want to adopt sustainability nor necessarily be able to. Furthermore, firms cannot have the same level (depth) of relationship with each customer.

Furthermore, moving incumbents up the rungs (or across in Fig. 8) is not always feasible (Richardson et al., 2015). Identifying 'suspects' and/or 'lurkers' may be difficult prior to establishing contact. Companies with traditional and online positions may find mixing the segment terminologies causes confusion. Many of the values attributed to sustainable segments change from generation to generation, depend on involvement and vary across sectors. For example, Generation $\mathrm{Z}$ often display high levels of environmental concern however recent studies suggest some Millenials may not (Bonera et al., 2020). Sectoral differences will also influence the viability of sustainable segments. Depending on the segments the stakeholder influence within industries differs with quality-oriented companies perceiving more pressure from stakeholders and consumers. They are more inclined to adopt SM strategies. However, companies in the mid-tier and lower-price segments perceive less stakeholder pressure and are less inclined to take up SM strategies (Belz \& Schmidt-Riedeger, 2010).

Put simply, the SM Loyalty Ladder should help companies to align their values with their segments. It presents different challenges to the BAU ladders (Fig. 5) as assume those at the bottom (say 'suspect' or lurker) are uncommitted, perhaps indifferent or ambivalent about the brand (Harridge-March \& Quinton, 2009). Whereas Critical Scholars would argue that those at the bottom of the SM Loyalty Ladder, say Libertarians, may have principled reasons for their attitudes and behaviours. Some consumers may have "negative moral values, generally associated with people who indulge in superfluous, not strictly necessary purchases, like those who buy luxury products" (Guido et al., 2020, p. 38). Someone who self-identifies as an "ecowarrior' (Fig. 6) chooses to value ecological considerations above all else (Young et al., 2010). Marketers may not be able to move these up the ladder to the ultimate sustainable stakeholder status. That said, the middle ground could be fruitful as prosocial consumers could be encouraged to be more environmentally friendly and thus migrate towards being pro eco/social. If they are satisfied and advocate loyalty to brands that are committed to ethical and environmental causes, they may evolve into Sustainable Stakeholders.

\section{Conclusions}

The concepts of orientations, segmentation, mapping stakeholders and loyalty are not new. Indeed, they are as old as marketing itself. Sustainability however represents a nascent, growing area of study which some consider a megatrend. This study has improved conceptualisation of Sustainable Marketing by building on the definitions of its predecessors, namely Social and Societal Marketing. It argues that Sustainable Marketing (SM) is the preferred term (to Sustainability or 
Sustainability-driven Marketing) and in doing so reduces definitional ambiguity. SM is more than the marketing of sustainability, rather it represents a holistic orientation. In Marketing Oriented (MO) companies, the customer should be placed at the heart of all key decisions. Adapting this to have an SMO involves being principled and is predicated on re-investing profits into ethically and ecologically sound practices. This paper is located in the Critical School however the adaptation of existing models herein can build a bridge with the Developmental School of thought. In doing so it encourages Marketers to adopt a reflective critical, approach when using loyalty techniques.

This paper has critiqued the BAU building blocks for Loyalty particularly the traditional segmentation frameworks and loyalty ladders. These form a chain which is only as strong as its weakest link. In unsustainable companies these activities must still be implemented well. To be a sustainable company, they should be predicated on the TBL, adopting good Internal Marketing and their IMC must feature continuous dialogues with stakeholders. Ultimately this is the only way to resolve the tensions between customers, stakeholders, companies' requirements, society's long run interests and the need for balance.

The traditional tools and frameworks are well known to academics and practitioners alike. That said, there is little research carried out into increasing the adoption of TBL-based sustainability by adapting these tools and frameworks. This is evident in most Business Schools where teaching is predicated on the BAU (bottom-line) loyalty models. Clearly this has to change as society strives to become more sustainable. Hence, this paper offers coherent arguments for adapting existing loyalty models and frameworks to incorporate Elkington's TBL. The TBL-based models herein provide extensive potential for future research.

It is important to recognize that different segments (Figs. 6, 8) will have unique barriers to adoption and seek different benefits prior to behaviour change (White et al., 2019). Eco-warriors (see Fig. 6) distrust marketer-dominated communications therefore the IMC could use testimonials from green customers, 'independent' thirdparty information (say from greenpeace) and/or credible celebrities (Richardson, 2015; Young et al., 2010). Highly ethical and/or ecological customers would expect a depth of information involving all aspects of the product or service and would be willing to join online communities where they can express their 'independent' views (ibid). If the segment was deemed pro-eco-social the information credibility would still be a major issue however a balance between 'green' and 'societal' sources (e.g. Amnesty International) would be needed.

These instruments (Figs. 6, 7, 8) can provide insights into relationships, contribute to refined stakeholder communications and indicate area where processes can be improved. Improved segmentation will help in the formation of the company strategies and values that are consistent with the assumptions of the SD concept (Rudowska, 2018). Sustainable solutions require multi-stakeholder engagement and involve making incremental or radical changes to consumption and production patterns (ibid). This study takes an incremental approach by adapting extant BAU models to create a TBL-based suite of loyalty tools that enables better decision-making. Their creation could act as a springboard for academics and practitioners alike. 


\section{Future research}

Organizations must proactively gather information about consumers' interests (Mercadé-Melé et al., 2018) and behaviour (Jackson, 2005). Arguably, the most significant shortcoming of the mainstream approach to consumer behaviour is the failure to recognise that "consumption encompasses a range of behaviours that both precede and follow purchase" (Peattie \& Belz, 2010, p. 11). Sustainable consumption, unlike its traditional predecessor, does not end at the sale, rather it ends "at the stage of disposal of the side effects, recycling and detritus of consumption" (Rudowska, 2018, p. 72). As little research exists using TBL-based mechanisms to enable sustainable adoption, the SST (Fig. 6), APPROVES framework (Fig. 7) and SM loyalty ladder (Fig. 8) could inform future studies, for example, analysing why sustainable values may have a weaker influence on consumer decision making processes (Jackson, 2005); attitudes post-usage; motivation to be greener or more ethical; demographic characteristics, finance, habit, lack of information, lifestyles, or trading off between different ethical factors (Young et al., 2010); how consumers' perceptions shape sustainable consumption (ibid); the extent to which personality influences sustainable consumption; trust and consumer involvement in sustainable practices (Bertoli et al., 2020). Future research could relate to sustainable STP approaches or to investigate the extent to which sustainable consumers feel 'locked in' (Harrison et al., 2012; Murray \& Haubl, 2007; Sanne, 2002). These factors are not prioritised and future research could revolve around the extent to which such factors influence each other (or do not).

Apropos organisational behaviour, research could be undertaken regarding whether other traditional BAU frameworks need to be adapted or how the frameworks herein can be applied e.g. the extent to which adoption of TBL-based approaches can be inculcated into Corporate Culture (CC) or Internal Marketing (Rafiq \& Ahmed, 2000) and ultimately whether sustainability adoption generates competitive advantage. Different strands of $\mathrm{CC}$ research could allude to branding. Similarly, the impact on IMC (Porcu et al., 2020) would be worthy of study. What challenges does the SM Loyalty Ladder (Fig. 8) present apropos internal communications? How would communications need to be tailored internally and particularly for "Boundary Spanning Employees" (Richardson, 2020, p. 223) who interact regularly with customers and prospects. Research could investigate STP apropos the appropriate tailored Mix required and the impact upon Segmentation, Targeting and Positioning as key aspects of strategic SM adoption (Rudowska, 2018). Clearly, any such studies could be extended across sectors and different countries.

Author contributions Not applicable—sole author.

Funding Not applicable.

Data availability Not applicable.

Code availability Not applicable. 


\section{Declarations}

Conflict of interest There are no conflicts of interest.

Open Access This article is licensed under a Creative Commons Attribution 4.0 International License, which permits use, sharing, adaptation, distribution and reproduction in any medium or format, as long as you give appropriate credit to the original author(s) and the source, provide a link to the Creative Commons licence, and indicate if changes were made. The images or other third party material in this article are included in the article's Creative Commons licence, unless indicated otherwise in a credit line to the material. If material is not included in the article's Creative Commons licence and your intended use is not permitted by statutory regulation or exceeds the permitted use, you will need to obtain permission directly from the copyright holder. To view a copy of this licence, visit http://creativecommons.org/licen ses/by/4.0/.

\section{References}

Agle, B. R., Donaldson, T., Freeman, R. E., Jensen, M. C., Mitchell, R. K., \& Wood, D. J. (2008). Dialogue: Toward superior stakeholder theory. Business Ethics Quarterly, 18(2), 153-190.

Agle, B.R., \& Mitchell, R.K. (2008) Introduction: Recent research and new questions from academy of management 2007 symposium

Aksoy, L. (2013). How do you measure what you can't define? The current state of loyalty measurement and management. Journal of Service Management, 24(4), 356-381.

Andreasen, A. R. (1993). Presidential address: A social marketing research agenda for consumer behavior researchers. Association for Consumer ResearchIn M. Rothschild \& L. McAlister (Eds.), Advances in consumer research (Vol. 20, pp. 1-5)

Armstrong, G., \& Kotler, P. (2012). Marketing: An introduction (11th ed.). Boston.

Barkemeyer, R. (2009) Beyond compliance - below expectations? CSR in the context of international development. Business Ethics: A European Review 18

Barkemeyer, R., Figge, F., Holt, D., \& Hahn, T. (2009). What the papers say: Trends in sustainability: A comparative analysis of 115 leading national newspapers. Worldwide Journal of Corporate Citizenship Issue, 33, 69-86.

Belz, F.-M., \& Peattie, K. (2009). Sustainability marketing: A global perspective. Wiley.

Belz, F.-M., \& Schmidt-Riediger, B. (2010). Marketing strategies in the age of sustainable development: Evidence from the food industry. Business Strategy and the Environment., 19, 401-416. https://doi. org/10.1002/bse.649

Bertoli, G., Busacca, B., \& Imperato, M. (2020). (2020) Premium private label: How product value, trust and category involvement influence consumers willingness to buy. Italian Journal of Marketing, 2020, 143-161. https://doi.org/10.1007/s43039-020-00012-7

Bitner, M. J. (1995). Building service relationships: It's all about promises. Journal of the Academy of Marketing Sciences., 23(4), 246-251.

Bonera, M., Codini, A. P., \& Miniero, G. (2020). The great Millennials' trouble: Leading or confused green generation? An Italian insight. Italian Journal of Marketing, 2020, 289-308. https://doi.org/ 10.1007/s43039-020-00015-4

Brassington, F., \& Pettitt, S. (2007). Essentials of marketing (2nd ed.). Pearson Education.

Brown, S. (1995). Postmodern marketing. Routledge.

Brownlie, D., \& Saren, M. (1992). The four Ps of the marketing concept: Prescriptive, polemical, permanent and problematical. European Journal of Marketing, 26(4), 34-47.

Brownlie, D., Saren, M., Wensley, R., \& Whittington, R. (1999). Rethinking marketing: Towards critical marketing accountings. Sage.

Carpenter, J. M., \& Moore, M. (2006). Consumer demographics, store attributes, and retail format choice in the US grocery market. International Journal of Retail \& Distribution Management., 34(6), 434-452.

Christopher, M., Payne, A., \& Ballantyne, D. (1991). Relationship marketing: Bringing quality customer service and marketing together. Butterworth Heinemann. 
Clarkson, M. B. E. (1995). A stakeholder framework for analyzing and evaluating corporate social performance. Academy of Management Review, 20(1), 92-117.

Coppola, C., Vollero, A., Conte, F., \& Siano, A. (2020). (2020) Self-production in an upcycling online community: Shared knowledge, collaborative ideas and creation of value. Italian Journal of Marketing., 2020, 231-248. https://doi.org/10.1007/s43039-020-00010-9

Crittenden, V. L., Crittenden, W. F., Ferrell, L. K., Ferrell, O. C., \& Pinney, C. C. (2011). Market-oriented sustainability: a conceptual framework and propositions. Journal of the Academy of Marketing Science, 39, 71-85. https://doi.org/10.1007/s11747-010-0217-2

Dibb, S., Simkin, L., Pride, W. M., \& Ferrell, O. C. (2006). Marketing concepts and strategies, Houghton Mifflin.

Dick, A. S., \& Basu, K. (1994). Consumer loyalty: Towards an integrated conceptual approach. Journal of the Academy of Marketing Science, 22(2), 99-113.

Elkington, J. (1998). The 'triple bottom line' for 21 st century business. In R. Starkey \& R. Welford (Eds.), Published in the Earthscan Reader in Business \& Sustainable Development (2001). Earthscan Publishing.

Emery, B. (2012). Sustainable marketing. Pearson Education.

Freeman, R. E. (1984). Strategic management: A stakeholder approach. Pitman.

Freeman, R.E. (2008) Ending the so-called "Friedman-Freeman" debate article from Academy of Management 2007 Symposium printed in Agle, B.R., Donaldson,T., Freeman, R.E., Jensen, M.C.

Fuller, D. A. (1999). Sustainable marketing: Managerial-ecological issues. Sage.

Garcia, R., Wilner, S.J.S., Dacko, S. \& Claudy, M. (2014) A business model innovation approach to sustainable market orientation. In Proceedings of international society for professional innovation management. (ISPIM) conferences. Issue 25, pp. 1-8.

Gomez-Trujillo, A. M., Velez-Ocampo, J., \& Gonzalez-Perez, M. A. (2020). A literature review on the causality between sustainability and corporate reputation. What goes first? Management of Environmental Quality: an International Journal, 31(2), 406-430. https://doi.org/10.1108/ MEQ-09-2019-0207

Gosnay, R. M., \& Richardson, N. (2008). Develop your marketing skills. Kogan Page.

Guido, G., Amatulli, C., Peluso, A. M., De Matteis, C., Piper, L., \& Pino, G. (2020). Measuring internalized versus externalized luxury consumption motivations and consumers' segmentation. Italian Journal of Marketing, 2020, 25-47. https://doi.org/10.1007/s43039-020-00002-9

Harridge-March, S., \& Quinton, S. (2009). Virtual snakes and ladders: Social networks and the relationship loyalty marketing ladder. The Marketing Review, 9(2), 171-181.

Harris, L. C., \& Goode, M. M. H. (2004). The four levels of loyalty and the pivotal role of trust: A study of online service dynamics. Journal of Retailing, 80, 139-158.

Harrison, M. P., Beatty, S. E., Reynolds, K. E., \& Noble, S. N. (2012). Why customers feel locked into relationships: Using Qualitative research to uncover the lock-in factors. Journal of Marketing Theory and Practice, 20(4), 391-406. https://doi.org/10.2753/MTP1069-6679200403

Hart, S. L. (1997). Beyond greening: Strategies for a sustainable world. Harvard Business Review., $75(1), 66-76$.

Hult, G. T. M. (2011). Market-focused sustainability: market orientation plus! Journal of the Academy of Marketing Science., 39, 1-6. https://doi.org/10.1007/s11747-010-0223-4

ISMA (2021) What is social marketing? Online article. https://isocialmarketing.org/ [Accessed 2809 $21]$.

Jackson, T. (2005) Motivating Sustainable Consumption- a review of evidence on consumer behaviour and behavioural change; a report to the Sustainable Development Research Network January 2005. Funded by the Economic and Social Research Council's Sustainable Technologies Programme $(S T P)$

Jensen (2008) Non-rational behavior, value conflicts, stakeholder theory, and firm behavior article from Academy of Management 2007 Symposium printed in Agle, B.R., Donaldson, T., Freeman, R.E., Jensen, M.C., Mitchell, R.K., \& Wood, D.J. (2008) Dialogue: Toward superior stakeholder theory. Business Ethics Quarterly(Vol. 18, No. 2, pp.153-190).

Jones, B., Bowd, R., \& Tench, R. (2009). Corporate irresponsibility and corporate social responsibility: Competing realities. Social Responsibility Journal, 5(3), 300-310.

Jones, P., Clarke-Hill, C., \& Comfort, D. (2008). (2009) Marketing and sustainability. Marketing Intelligence \& Planning, 26(2), 123-130. https://doi.org/10.1108/02634500810860584 
Jung, J., Kim, S. J., \& Kim, K. H. (2020). Sustainable marketing activities of traditional fashion market and brand loyalty. Journal of Business Research, 120, 294-301. https://doi.org/10.1016/j. jbusres.2020.04.019

Kemper, J. A., \& Ballantine, P. W. (2019). What do we mean by sustainability marketing? Journal of Marketing Management. https://doi.org/10.1080/0267257X.2019.1573845

Kennedy, A.-M. (2015). Macro-social marketing. Journal of Macromarketing, 2015, 1-12.

Kohli, A. K., \& Jaworski, B. J. (1990). Market orientation: The construct, research propositions and managerial implications. Journal of Marketing, 45(2), 1-18.

Kotler, P., \& Armstrong, G. (2006). Marketing: an introduction (8th ed.). Prentice Hall.

Kotler, P., \& Lee, N. (2005). Corporate social responsibility. Wiley.

Kotler, P., \& Levy, S. J. (1969). Broadening the concept of marketing. Journal of Marketing, 33(1), 10-15. https://doi.org/10.2307/1248740

Kumar, V., Rahman, Z., Kazmi, A. A. \& Goyal, P. (2012). Evolution of sustainability as marketing strategy: Beginning of new era. International Conference on Emerging Economies - Prospects and Challenges. (ICEE-2012). Procedia - Social and Behavioral Sciences (Vol. 37 pp. 482-489). https://doi.org/10.1016/j.sbspro.2012.03.313

Legere, A., \& Kang, J. (2020). 2020) The role of self-concept in shaping sustainable consumption: A model of slow fashion (2020. Journal of Cleaner Production, 258(120699), 1-12. https://doi.org/10. 1016/j.jclepro.2020.120699

Letza, S., Sun, X., \& Kirkbride, J. (2004). Shareholding versus stakeholding: A critical review of corporate governance. Corporate Governance, 12(3), 242-262.

Lubin, D. A., \& Esty, D. C. (2010). The sustainability imperative. Harvard Business Review, 88(5), 42-50. https://doi.org/10.1057/9780230115439

Mahmoud, M. A. (2016). (2016) Sustainable market orientation: a competitive strategic tool in an emerging economy context. Journal of Strategic Marketing, 24(7), 635-654. https://doi.org/10.1080/ 0965254X.2016.1149210

Margolis, J. D., \& Walsh, J. P. (2003). (2003) Misery loves companies: Rethinking social initiatives by business. Administrative Science Quarterly, 48, 268-305.

Martin, D., \& Schouten, J. (2012). Sustainable Marketing. Pearson Education Limited.

McDonald, M. (2017). Malcolm McDonald on marketing planning-understanding marketing plans and strategy (2nd ed.). London.

McDonagh, P., \& Prothero, A. (2014). Sustainability marketing research: Past, present and future. Journal of Marketing Management, 30(11-12), 1186-1219.

Mendes, J., Guerreiro, M. \& Valle, P. (2009) Sustainable planning for community venues. In R. Razaq \& J. Musgrave (Eds.) Chapter 15 in 'Event management and sustainability'. CABI

Mercadé-Melé, P., Molinillo, S., Fernández-Morales, A., \& Porcu, L. (2018). CSR activities and consumer loyalty: The effect of the type of publicizing medium. Journal of Business Economics and Management, 19(3), 431-455. https://doi.org/10.3846/jbem.2018.5203

Mitchell, R. K., Agle, B. R., \& Wood, D. J. (1997). Toward a theory of stakeholder identification and salience- defining the principle of who and what really counts. Academy of Management Review, 22(4), 853-866.

Mitchell, V. W., \& Harris, G. (2005). The importance of consumers' perceived risk in retail strategy. European Journal of Marketing, 39(7/8), 821-837.

Mitchell, R. W., Wooliscroft, B., \& Higham, J. (2010). Sustainable market orientation: A new approach to managing marketing strategy. Journal of Macromarketing., 30(2), 160-170. https://doi.org/10.1177/ 0276146710361928

Mitchell, R. W., Wooliscroft, B., \& Higham, J. (2013). Applying sustainability in national park management: balancing public and private interests using a sustainable market orientation model. Journal of Sustainable Tourism, 21(5), 695-715. https://doi.org/10.1080/09669582.2012.737799

Mittelstaedt, J. D., Shultz, C. J., Kilbourne, W. E., \& Peterson, M. (2014). (2014) Sustainability as megatrend: Two schools of macromarketing thought. Journal of Macromarketing., 34(3), 253-264. https://doi.org/10.1177/0276146713520551

Murray, K. B., \& Haubl, G. (2007). Explaining cognitive lock-in: The role of skill-based habits of use in consumer choice. Journal of Consumer Research, 34(1), 77-88.

Musgrave, J. \& Raj, R. (2009) Introduction to a conceptual framework for sustainable events. In R. Raj, \& J. Musgrave (Eds.) Chapter 1 'Event management and sustainability'. CABI 
Oates, C., McDonald, S., Alevizou, P., Hwang, K., Young, W., \& McMorland, L. (2008). Marketing sustainability: Use of information sources and degrees of voluntary simplicity. Journal of Marketing Communications, 14(5), 351-365.

Oliver, R. L. (1997). Satisfaction: A behavioural perspective on the consumer. Irwin/McGraw Hill.

Pacheco, D. F., Dean, T. J., \& Payne, D. S. (2010). Escaping the green prison: Entrepreneurship and the creation of opportunities for sustainable development. Journal of Business Venturing, 25(5), 464-480.

Parasuraman, A., Berry, L. L., \& Zeitmal, V. A. (1991). Perceived service quality as a customer based performance measure: An empirical examination of organisational barriers using an extended service quality model. Human Resource Management, 30(3), 335-364.

Peattie, K. (1992). Green marketing. Pitman Publishing.

Peattie, K., \& Belz, F.-M. (2010). Sustainability marketing: an innovative conception of marketing. Marketing Review., 5, 8-15.

Porcu, L., del Barrio-García, S., Kitchen, P. J., \& Tourky, M. (2020). The antecedent role of a collaborative vs. a controlling corporate culture on firm-wide integrated marketing communication and brand performance. Journal of Business Research, 119, 435-443. https://doi.org/10.1016/j.jbusres.2019. 10.049

Prothero, A., \& McDonagh, P. (2015). Introduction to the special issue: Sustainability as megatrend II. Journal of Macromarketing, 35(1), 7-10. https://doi.org/10.1177/0276146714556818

Rafiq, M., \& Ahmed, P. (2000). Advances in internal marketing concept: Definition, synthesis and extension. Journal of Services Marketing, 14(6), 449-462.

Ramus, C. A., \& Montiel, I. (2005). When are corporate environmental policies a form of greenwashing? Business \& Society, 44(4), 377-414.

Richardson, N.A. (2015) The adoption of sustainable marketing practices within the UK music festivals sector. $\mathrm{PhD}$ thesis, University of Leeds. https://etheses.whiterose.ac.uk/13578/

Richardson, N., James, J., \& Kelley, N. (2015). Customer-centric marketing: Supporting sustainability in the digital age. Kogan Page.

Richardson, N. (2018). Entrepreneurial insights into sustainable marketing: A case study of U.K. music festivals. Strategic Change. Special Edition: THe Creation of Value through Sustainable Development. Part 1, 2018, 559-570. https://doi.org/10.1002/jsc.2239

Richardson, N., \& Cassop Thompson, M. (2019). A new positioning framework for organizational value: Juxtaposing organizational value positions with customer centricity. Strategic Change Special Edition: Sustainable Business Models., 2019, 1-10. https://doi.org/10.1002/jsc.2253

Richardson, N. (2020). Sstainable marketing planning. Routledge.

Rudowska, E. (2018) From sustainable market orientation to sustainability marketing. (2018). In E. Rudowska (Ed.)Chapter 3 in The Sustainable Marketing Concept in European SMEs-Insights from the Food \& Drink Industry. Emerald. https://doi.org/10.1108/978-1-78754-038-520180004

Sanne, C. (2002). Willing consumers- or locked in? Policies for a sustainable consumption. Ecological Economics, 42(2002), 273-287.

Sheehan, B. (2010). The economics of abundance: Affluent consumption and the global economy. Edward Elgar.

Sinčić Ćorić D., Lučić A., Brečić R., Šević A., Šević Z. (2020) An exploration of start-ups'sustainable marketing orientation (SMO) Industrial Marketing Management;91:176-186. https://doi.org/10. 1016/j.indmarman.2020.09.002

Skov, L. \& Meier, J. (2011) Configuring sustainability at fashion week. Chapter 11 in Moeran, B. \& Strandgaard Pedersen, J. (2011) Negotiating values in the creative industries-fairs, festivals and competitive events. Cambridge University Press

Starkey, R., \& Welford, R. (2001). The earthscan reader in business \& sustainable development. Earthscan Publishing.

Tadajewski, M., \& Brownlie, D. (2008). Critical marketing-issues in contemporary marketing. Wiley.

van Dam, Y. K., \& Apeldoorn, P. A. C. (1996). Sustainable marketing. Journal of Macromarketing, $16(2), 45-56$.

Verhoef, R. (2003). Understanding the effect of customer relationship management on customer share development. Journal of Marketing, 63, 30-45.

Walsh, J. P., Weber, K., \& Margolis, J. D. (2003). Social issues and management: Our lost cause found. Journal of Management., 29, 859-881. 
WCED (1987) The Brundtland Commission report world commission on environment and development. https://sustainabledevelopment.un.org/content/documents/5987our-common-future.pdf [Accessed 30-09-21]

White, K., Habib, R., \& Hardisty, D. J. (2019). How to SHIFT consumer behaviors to be more sustainable: A literature review and guiding framework. Journal of Marketing, 83(3), 22-49. https://doi. org/10.1177/0022242919825649

Wiscicka-Fernando, M. (2018) Sustainability marketing tools in small and medium enterprises, Chapter 4. In E. Rudowska (Eds.) The sustainable marketing concept in European SMEs-insights from the food \& drink industry. Bingley, Emerald. https://doi.org/10.1108/978-1-78754-038-520180005

Worthington, I. (2013). Greening business- Research, theory \& practice. OUP.

Young, W., Hwang, K., McDonald, S., \& Oates, C. (2010). Sustainable consumption: Green consumer behaviour when purchasing products. Sustainable Development., 18, 20-31.

Publisher's Note Springer Nature remains neutral with regard to jurisdictional claims in published maps and institutional affiliations.

\section{Authors and Affiliations}

\section{Neil Richardson ${ }^{1}$}

Neil Richardson

n.richardson@leedsbecket.ac.uk

1 Leeds Business School, Leeds Beckett University, The Rose Bowl, Portland Gate, Leeds LS1 3HB, UK 